\title{
Dental amalgam fillings and the use of technological devices as an environmental factor: Updating the cumulative mercury exposure-based hypothesis of autism
}

Dear Editor,

The molecular basis of autism spectrum disorders (ASD) still remains obscure and little is known about the specific gene-environment interactions that may increase the prevalence of the disorder. ${ }^{[1,2]}$ There has been a lot of controversy in the past regarding the association of thimerosal, mercury $(\mathrm{Hg})$-containing preservative in vaccines, and the increased probability of developing autism among children. With the lack of information concerning amalgam hazards, it has been suggested that the traces of $\mathrm{Hg}$ found in dental fillings could be considered safe; however, this may not be true since the link between $\mathrm{Hg}$ exposure and autism also needs to include the individual's susceptibility. In 2011, as a more consensual theory, we alternatively proposed the "cumulative $\mathrm{Hg}$ exposure-based hypothesis" which considers not only one but the total contribution of different environmental sources of this element, such as (i) maternal amalgam fillings, (ii) pollution, (iii) food, and also (iv) thimerosal-preserved vaccines together with a genetic/biochemical susceptibility to remove $\mathrm{Hg}$ from the body. ${ }^{[3]}$

Common technological devices (e.g., mobile phones, mobile base stations, and magnetic resonance imaging machines and other wireless devices) produce electromagnetic fields (EMFs). Neurobehavioral and neurodevelopmental symptoms such as retarded memory, learning, cognition, and attention have been attributed to EMF exposure. ${ }^{[4]}$ Of note, these symptoms are also attributed to ASD and attention deficit hyperactivity disorders. A recent in vivo study observed autism-relevant social abnormalities in mice exposed to extremely low-frequency EMFs during perinatal development. ${ }^{[5]}$ This may indicate a potential direct link between EMFs and the prevalence of autism in specific window/s of vulnerability that would deserve further investigation. An indirect link might be also plausible since high-field magnetic resonance and microwave radiation emitted by common mobile phones have been reported to increase the release of mercury from dental amalgam fillings. ${ }^{[6,7]}$ These recent evidence (2014), far from being conflictive, is consistent with our previous cumulative $\mathrm{Hg}$ exposure-based hypothesis of ASD (2011) and could be included as the fifth (v) additional environmental factor, synergistically contributing to the release of $\mathrm{Hg}$ in mothers with dental amalgam fillings, and increasing the probability of developing and/or aggravating autism among children. Nevertheless, this updated version of our hypothesis would require more extensive clinical confirmation and supporting evidence.

\section{Financial support and sponsorship}

Nil.

\section{Conflicts of interest}

There are no conflicts of interest.

\section{Isadora Argou-Cardozo ${ }^{1}$, José Antonio Cano Martín², Fares Zeidán-Chuliá ${ }^{3}$}

1Specialization Course in Public Management and Regional
Development, Faculty of Administration and Tourism, Federal
University of Pelotas (UFPel), Pelotas, RS, Brazil,
2Deusto Business School, University of Deusto, Madrid, Spain,
32Department of Periodontology, Institute of Dentistry, Faculty of
Medicine, University of Turku, Turku, Finland
Correspondence: Dr. Fares Zeidán-Chuliá
Email: fzchulia.biomed@gmail.com

\section{REFERENCES}

1. Zeidán-Chuliá F, Rybarczyk-Filho JL, Salmina AB, de Oliveira BH, Noda M, Moreira JC. Exploring the multifactorial nature of autism through computational systems biology: Calcium and the Rho GTPase RAC1 under the spotlight. Neuromolecular Med 2013;15:364-83.

2. Zeidán-Chuliá F, Salmina AB, Noda M, Verkhratsky A. Rho GTPase $\mathrm{RAC} 1$ at the molecular interface between genetic and environmental factors of autism spectrum disorders. Neuromolecular Med 2015;17:333-4.

3. Zeidán-Chuliá F, Gursoy UK, Könönen E, Gottfried C. A dental look at the autistic patient through orofacial pain. Acta Odontol Scand 2011;69:193-200

4. Sage C, Burgio E. Electromagnetic fields, pulsed radiofrequency radiation, and epigenetics: How wireless technologies may affect 


\section{Letter to Editor}

childhood development. Child Dev 2017. doi: 10.1111/cdev.12824.

5. Alsaeed I, Al-Somali F, Sakhnini L, Aljarallah OS, Hamdan RM, Bubishate SA, et al. Autism-relevant social abnormalities in mice exposed perinatally to extremely low frequency electromagnetic fields. Int J Dev Neurosci 2014;37:58-64.

6. Mortazavi SM, Neghab M, Anoosheh SM, Bahaeddini N, Mortazavi G, Neghab P, et al. High-field MRI and mercury release from dental amalgam fillings. Int J Occup Environ Med 2014;5:101-5.

7. Mortazavi G, Haghani M, Rastegarian N, Zarei S, Mortazavi SM. Increased release of mercury from dental amalgam fillings due to maternal exposure to electromagnetic fields as a possible mechanism for the high rates of autism in the offspring: Introducing a hypothesis. J Biomed Phys Eng 2016;6:41-6.

This is an open access article distributed under the terms of the Creative Commons Attribution-NonCommercial-ShareAlike 3.0 License, which allows others to remix, tweak, and build upon the work non-commercially, as long as the author is credited and the new creations are licensed under the identical terms.

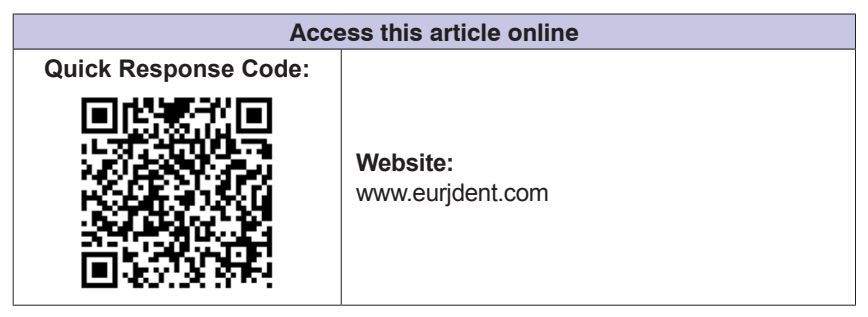

How to cite this article: Argou-Cardozo I, Cano Martín JA, Zeidán-Chuliá F. Dental amalgam fillings and the use of technological devices as an environmental factor: Updating the cumulative mercury exposure-based hypothesis of autism. Eur J Dent 2017;11:569-70.

DOI: 10.4103/ejd.ejd_222_17 